\title{
Teaching Digital Games in Preservice Teacher Education
}

\author{
Reynold Redekopp \\ University of Manitoba, Canada
}

\begin{abstract}
Using digital games in the $21^{\text {st }}$ Century $(21 C)$ classroom, not only makes learning more fun for students, but ostensibly assists students in learning both content and 21 st century skills. Some of the $21 \mathrm{C}$ skills that promoters of digital games claim are enhanced by using digital games are: problemsolving, motivation, communication, cooperation and collaboration. While there is still a lot of research to be done in terms of the benefits of using games in the classroom, this study sought to examine the research where games are being used in preservice teacher education programs and what some of the critical variables are that prospective teachers need to be aware of if they want to use digital games in their future classrooms. The results show that there are currently no specific digital game based courses for preservice teachers in Canadian faculties of education, and in fact many faculties require no technology related courses at all. There are, no doubt, courses that integrate digital games in the learning process, but it is not at all clear if, even in such cases, that preservice teachers are being made aware of the critical role that teachers play in making the use of games successful.
\end{abstract}

\section{Introduction}

An online survey of the courses shown on the web sites of Canadian Faculties of Education reveals that there are no specific courses in preservice education related to digital game based learning. This is not particularly surprising as there is much other material to cover in a one or two year program. What is surprising is that a number of faculties have made technology in education courses optional or dropped them altogether from their programs. This presumably is because they assume that technology is being infused into the other courses. Many years of experience with computers in education suggest that this is not the case, and therefore, the use of digital games is likely seldom discussed or modeled.

The lack of discussion is often based on the misconception that "students these days know all these things." And while in fact our preservice teachers for the most part know how to text, chat, game (mainly apps), search (poorly), and 'Facebook', they have almost no idea of the pedagogical value of any of the things they supposedly know and, obviously, nothing of the many things outside of their personal experience. As Wilson [1] puts it: "Even teachers who are gamers do not intuitively know how to use games in the classroom." (p. 2)

In their study of preservice teachers, Schrader et al [2] found:

What is evident from these data is that while this population has been exposed to video games since a very early age and values games for social reasons, most preservice teachers either have not experienced or no longer engage in the social aspects of gaming and gaming communities, specifically those relating to MMOGs. (p. 3)

There is limited research that describes the use of digital games with preservice teachers, but there are some surprising findings.

Anderson and Barnett [3] used the video game Supercharged to teach basic physics ideas to preservice elementary teachers. And although the experimental group did significantly better on the post-test, they felt they were not 'learning' because the form of learning was non-traditional. Parents and administrators of K-12 students are likely to feel the same way if they are not properly informed of the purpose of the games played in classrooms

Also, playing the Supercharged game did not encourage students to engage in further exploration of the topic. The authors suggest that game developers build meta-cognitive/reflective activities into the games to help students feel that they are 'learning.' This is also a part of the role of the teacher, as will be discussed later.

Anderson and Barnett [3] found that another important connection is the role of games to highlight student misconceptions. This can lead to discussions and further demonstrations to correct the problems. This is another critical piece for teachers. Teachers need to set up discussion spaces, both in class and online, for students to exchange information and ideas. 
Babour, Evans and Toker [4] studied how preservice teachers made connections between COTS (consumer off-the-shelf) games and the social studies curriculum. The students purchased a game and played a minimum of 24 hours and recorded their reactions to playing the game. They found that students could readily identify connections between the games and the curriculum but had problems deciding how they could implement the use of games. They were more successful if the games had an obvious relationship with the curriculum.

A key reminder from Van Eck [5] is that games are not the 'silver bullet' or cure-all for education. Teachers have to figure out what will work with different students, courses and classroom environments. He also describes the three ways that teachers use games in education: using COTS that fit the curriculum, having students make games to demonstrate or teach content, or have developers make games specific to the curriculum (the most expensive option by far).

Students of all ages are now able to create interesting games and be involved in setting up the problem scenario and developing the kinds of skills needed to make the game work. Some of the great free options are Kodu, Scratch, Game Maker, 12Blocks, Logo, and GameStar Mechanic. Students can easily create a fun and working game in a short period of time. They also get lots of practice using deductive logic as they try to find the problems that prevent their games form working properly. This encourages a certain type of thinking highly valued by many educators, but we will discuss some of the limitations of this later.

Egenfeldt-Nielson [6] adds a discussion to the adoption of digital games in relation to Rogers diffusion of innovation theory - advantage over other methods, compatibility, complexity, trialability (trying without committing) and observability (seeing results). The trialability factor is often an issue with COTS games, including ones developed for tablets such as the iPad. For many games there is no trial version - you pay for it and hope it is good. Other games offer a free version that gives you a very limited level of the game to entice you to buy the complete package. Still other games are free, but you have to pay for add-ons such as more characters, background, tools, etc. This can rapidly increase costs for students or the school.

Finally, as Ito and Bittanti [7] point out, there are consistent (and mostly unjustified) fears of increasing violence in kids who are gamers. This can inhibit teachers from attempting to use games. Teachers obviously need to choose games carefully and then inform and educate parents and administrators as to how they will be used and what gains can be accomplished - and that what kids get from games is strongly connected to their social ecology and not necessarily the content of the games. Again this is a key aspect of the teacher's role in using games: to construct/adapt that social ecology to achieve the intended aims. There are many games that preservice teachers can use that do not contain or promote violence or raise other common social concerns and they should focus on these rather than the most current popular games.

So, why teach games to preservice teachers? There are some motivational and learning benefits to using games in the classroom. There are however no automatic gains just from playing the games. Nor is it obvious to young teachers which games will be most effective or how to judge whether a game might promote the kinds of learning hoped for. Preservice teachers need to:

- $\quad$ know how to break stereotyped perceptions of games and understand the barriers involved in trying to use them

- have examples of games that work

- know how to build the classroom infrastructure for games to be effective

- explore teacher roles in using games effectively to achieve both curricular and $21 \mathrm{C}$ goals

- know how to prepare administrators and parents to understand the use of the games.

- Recognize the emphasis or bias inherent in any game

\section{Stereotypes and Barriers}

Egenfeldt-Nielsen [8] interviewed two teachers using a game, Europa Universalis, in a history course. They found that there are many practical barriers: time schedule, physical setting, class expectations, teacher background, genre knowledge, technical problems, inexperience with group work, teacher preparation, perception of games, class size and knowledge of and experience with the game itself.

This is a lot for a teacher to deal with but there were payoffs. Students found the interaction and talking about how to solve problems with the teacher to be very worthwhile. But this only happens if the teacher is aware that students will progress at different rates, needing hints for the more subtle play in the game and that game examples must be used in their 'non-game' teaching. Preservice teachers cannot be expected to 'intuitively' figure these issues out on their own.

Preservice teachers must also be made aware of issues of stereotypes in games and be prepared to recognize them and proactively discuss these with 
their students and the community. While experienced teachers may try to encourage a deeper understanding in their students by using controversial games that display sexist or racial stereotypes, preservice teachers should probably avoid these obvious problem areas.

Inexperienced teachers should however be aware of some of the more subtle issues and biases that will be inherent in any games they choose. Every game will display a bias. Bias is not necessarily a pejorative term, it simply means that every game contains a point of view about the world and how it should work. Games that are designed to help students experience running a business will contain a bias about the importance of a business and will, by its very design, display a bias of how a business should be organized, what the goals should be and how to set priorities. Business development games do not promote the value of charitable donations or community contributions. Either the game thinks these are assumed values or that they truly interfere with running a business. This is not necessarily 'evil' but something that teachers and students might want to discuss as they play the game.

Games that promote social responsibility and action tend to emphasize the distress of a situation in a foreign country and promote western valued-laden solutions to the problem. The game might encourage a democratic/capitalist solution for a country that doesn't have the experience or education system necessary to sustain such a solution. So when students want to pour money into a problem and see that as a main component of the solution, the preservice teacher will have to know that there are consequences to any solution their students propose and help them explore these.

Even a seemingly innocuous game that explores a science concept such as the circulatory system carries a bias. In this case the preservice teacher should recognize the scientific concepts of isolating and naming individual parts and trying to control one of variable at a time. This is a western, objective way of viewing the body and its systems but there are more holistic ways of viewing the body which are less inclined to just treat symptoms and find an immediate fix and more inclined to look at various factors and longer term solutions.

A cross-curricular example might come from a game about ecology and how best to manage a endangered area. There is an immediate bias simply in using the term 'manage.' This assumes that we should have control over a natural area and that we can and should exploit the resources we find there. The game may assume that economic growth is a priority and that the earth is simply a holding tank of resources for us to use. Young teachers may find themselves challenged by their community if they use such a game and fail to have a meaningful conversation with their students about these various issues.

These are all areas that require discussion among the teacher and students and the larger community. Yet, these are often the most difficult discussions to have because the bias is subtle, a part of how we naturally view the world. Our preservice teachers need to be assisted in recognizing that any game will present a bias, or point of view, and that they should always be considering alternate points of view.

\section{Teacher Roles When Using Digital Games}

Magnussen [9] observed two teachers who decided to implement a digital game called Homicide, in which students work as forensic experts. Magnussen found a number of different roles that the teachers have to juggle:

- Case supervisors - where the teacher was not an expert in all the facts

- Keeping the context and content connected (not dealing with technical info in the abstract)

- Balancing being the advisor in the game setting and being the professional teacher.

Introducing a game into the classroom environment can be a huge motivator and engage a number of students who are not interested in school or a particular subject. But engagement is a necessary but not sufficient condition to guarantee learning, especially the learning that is tied to the teacher's curriculum. The teacher needs to be actively involved in creating the conditions and dialogue that will enable transfer from the game to the curricular outcomes. This is a real challenge for many students, as was noted above by Anderson and Barnett [3].

Angela McFarlane [10] emphasizes that kids need gaming communities as part of the learning process. Just spending time playing with the technology is not enough. Some of our students (she estimates about $15 \%$ ) naturally have these communities at home and in their friend/parent contacts. The vast majority, while they may have a computer at home or a cell phone in their pockets, does not have such a learning community readily available. Teachers need to set up, promote, monitor and encourage this community, as well as continually bringing the game and curricular content together. This can be in the classroom, online, or both.

Students are not all the same and will progress through a game at vastly different rates. Some will have the game at home, or buy it, and may finish long before their classmates. Other will only be able to work on the game during class time and will take 
much longer to complete the game. The teacher will not be able to fully assist all these students personally and the classroom communities help deal with the differing time frames as students will support each other as they progress through a game.

Wilson [1] in a paper published by the Software Information Industry Association discusses best practices for using games in education and concludes that teachers are the key to success. Wilson starts with the premise that games have a positive impact and discusses their use from that perspective. One needs to bear in mind that the report sponsors have a vested interest in the results, but the report is worth examining with that in mind. The discussion indicates that:

- Teachers need to understand the purpose of the game and their own role

- $\quad$ IT support needs to be gained early on for installation and tech support

- Teachers need "teaching strategies related to blended learning. Mix game play with discussion, lecture, reading and writing to gain the most benefits."

- $\quad$ Start small and perhaps use groups of 2-4 and mix gamers with non-gamers

- "Pedagogically, games force collaborative decision making. Grouping helps reduce barriers to learning by grouping proficient gamers with non-gamers."

- Teachers need to be actively involved and moving around helping students and assessing progress. External validation is necessary.

- Online discussion boards can be useful, but must be monitored.

- In class discussion (large or small groups) is also useful

The report echoes the bias of $21 \mathrm{C}$ learning activists in the emphasis on group work, collaborative learning and problem solving/decision making where the teacher is a consultant rather than a provider of information. Again, this is not necessarily a bad 'bias' but we should be aware of it nonetheless as some school communities are not ready to embrace this style of learning and teaching.

\section{Assessment Issues}

Preservice teachers will also need to learn how to use different kinds of assessment and assessment tools. They will have some tools at their disposal for measuring gains in curricular areas, but will need to be shown ways to assess the more intangible areas of 21st C skills and report these meaningfully to parents (and to administrators satisfaction). Without this ability to report results, games will remain in the 'edutainment' category and continue to be marginalized.

As Chen and Michael [11] put it:

Both the medium of serious games itself and its newness create certain challenges that can make assessment difficult:

- With less emphasis on rote memorization of facts, the assessment obtained from traditional methods may not accurately reflect the learning gained from serious games.

- Open-ended simulations can support a wide range of possible solutions. Which one is more correct?

- When teaching abstract skills such as teamwork and leadership, how do you measure learning and/or improvements?

- What is "cheating" in the context of serious games?

Chen and Michael [11] argue that digital games must support measurement of levels or goals that students have achieved, how and why the student made choices and modifications during game play. This can be done through logging or tracking during the game and developing a good reporting system. But they also emphasize the need for teacher evaluation to validate the data collected and the data collection process: are students cheating or skipping stages by finding cheats/flaws in the game? They also need to be aware of the interaction of students in terms of teamwork, leadership and communication.

Hickey and Jameson [12] suggest that too much emphasis on rubrics moves control of the learning from the learner to the rubric and the person scoring it. Instead student reflection should be the initial focal point for assessment. A highly structured rubric simply becomes a checklist for students to attend to in order to get the marks they want.

Having games provide assessment of $21 \mathrm{C}$ skills would be extremely helpful for all teachers, and preservice teachers in particular. There is general agreement that problem solving, communication, collaboration, etc, are important skills for students to develop but until these skills are recorded and reported regularly they will be seen as less important than the content found on state, national and international tests. This makes it difficult for preservice teachers to argue for digital games because developing these $21 \mathrm{C}$ skills can be one of the real strengths of games.

\section{Ethical/Cultural Issues}

Finally, there are some more subtle issues that our preservice teachers need to be aware of in regard to 
culture, gender, technology and games. It turns out that the internet is not colour or gender blind. Ito, et al [13] point out the development of various cultural communities on the internet. It is natural and desirable that different groups and communities create information on the internet that represents their ideas, values, ways of thinking and language. To assume that the internet is value neutral is misleading in the extreme and exhibits a colonialist attitude. Zuckerman [14], in his TEDGlobal talk demonstrates some of the various non-English, non-white groups in Twitter and on the internet. He also talks about how we are only a click or two away from seeing and joining these groups. Zuckerman does not talk specifically about games, but the inference is that we need to become more aware of these communities and points of view so that we see our own biases and points of view more clearly.

Preservice teachers will need to be sensitive to the cultural influences of many educational games because they maintain a white, western bias toward areas such as the economy and the environment. Popular games in North America tend to promote democracy and capitalism, and view the earth as a storage depot for human need and consumption. One goal of technology is to be in control of nature, or at least to be able to predict nature more accurately. These games therefore tend to assume that the current technological approach to solving problems will be successful. There are other ways of thinking about the earth and our problems.

Antonio Lopez [15] illustrates differences in thinking between linear (white) and circular (aboriginal) thinking that lead to very different ways of dealing with problems. The linear model analyzes discreet bits of information, solves the piece of the problem and then inserts this partial solution back into the larger context. This often ignores the consequences of the first solution. Circular thinking tends to be much more relational and prefers problem solving to be more holistic or 'big-picture' in approach.

So simply ensuring that people of various skincolour are represented when students choose an avatar as their representative in the game does not deal with cultural issues at all. It simply adds a 'skin' (in this case literally) to the biases and assumptions of the game designers.

Preservice teachers also need to be able to analyze games and web sites with gender in mind. While the gender inequities are fairly easy to spot in many big commercial games (body shape and potential roles for example), they are subtler in many of the educational games because designers with a background similar to teachers develop them. And while designers have made great strides in trying to reduce the obvious gender imbalances of the past, teachers still need to be aware of the inherent bias that creeps in. As one of my female students commented on one game: "I can't make my avatar as big as I am. I'm large and I want my avatar to be large, but the game won't let me."

As with skin colour, simply allowing various body shapes only pretends to accommodate the limited roles that female characters often have to assume. Game designers have to do better and preservice teachers need to understand these assumptions so that they are incorporated into the classroom dialogue as students play the games.

\section{Conclusion}

Teachers play a critical role in the successful use of digital games in the classroom, and the student experience of it beyond the classroom. Digital games are being touted as an underutilized resource in $21 \mathrm{C}$ education and preservice teachers should be made aware of the potential and the issues of using digital games. Education programs should teach about and model the use of educational games for gaining curricular understanding, building 21C skills and assessing and reporting the results.

"Good pedagogy and instructional value is paramount in serious games. While games with educational content have existed for a long time, too many have relied on simplistic or unproven metrics. 'What's been missing is a pedagogy engine and an assessment engine,' Brazell says." (Chen and Michael [11]

The roles of the teacher in the successful use of games must be made clear to preservice teachers. Some of these are:

- Choosing games that the teacher can relate back to the content area and that promote $21 \mathrm{C}$ skills.

- Looking for game that promote alternate ways of thinking

- Setting the context for the game

- Informing administrators and parents of the purpose of playing the game

- Creating a safe climate for discussion, whether in class or online or both

- Helping students understand the bias or assumptions inherent in the game content and design

- Providing formative and summative assessment of both content learning and skill development.

- Reporting these assessments in meaningful ways to parents and administrators.

- Understand the type of problem solving they are emphasizing and work to balance 
multiple points of view about how to solve problems.

There are no clear indicators that this is being done in Canadian faculties of education - certainly there are no courses with digital games used as a main theme. Faculties need to deliberately plan for the integration of digital games into courses or develop digital game based courses.

\section{References}

[1] Wilson, L "Best Practices for Using Games \& Simulations in the Classroom Guidelines for K-12" Educators. Washington, DC: Software Information Industry Association, $2009 . \quad$ Print. $<$ http://www.siia.net/index.php?option=com_docman $\&$ task=doc_view\&gid=610\&tmpl=component $\&$ forma $\mathrm{t}=$ raw $\&$ Itemid $=59>$.

[2] Schrader, P. G. , Dongping Zheng, and Michael Young . "Teachers' Perceptions of Video Games: MMOGs and the Future of Preservice Teacher Education ." Innovate Online. Innovate, n.d. Web. 16 May 2012.<www.innovateonline.info/index. php?view=article $\& i d=125>$.

[3] Anderson, Janice, and Michael Barnett. "Using Video Games to Support Pre-Service Elementary Teachers Learning of Basic Physics Principles." Journal of Science Education and Technology, 20(4), 347-362 20.4 (2010): 347-362. Web. 16 May 2012. <http://www.springerlink.com/index/10.1007/s10956010-9257-0>.

[4] Barbour, Michael, and Mark Evans . "Making Sense of Video Games: Pre-Service Teachers Struggle with This New Medium." Michael Barbour. N.p., n.d. Web. 16 May 2012. <www.michaelbarbour.com/ research/pubs/site09-games.pdf>.

[5] Van Eck, Richard. "Digital Game-Based Learning: It's Not Just the Digital Natives Who Are Restless (EDUCAUSE Review) | EDUCAUSE.edu." EDUCAUSE Homepage | EDUCAUSE.edu. Educause, 15 Mar. 2006. Web. 28 Aug. 2012. $<$ http://www.educause.edu/ero/article/digital-gamebased-learning-its-not-just-digital-natives-who-arerestless>.

[6] Egenfeldt-Nielsen, Simon. "Future of Game-Based Learning." Future of Game-Based Learning. Simon Egenfeldt-Nielsen, 15 Oct. 2010. Web. 28 Aug. 2012. <www.egenfeldt.eu/papers/ecgbl10-egenfeldt.pdf>.

[7] Ito, Mizuko, and Matteo Bittanti. "GAMING." Hanging out, messing around, and geeking out: kids living and learning with new media. Cambridge, Mass.: MIT Press, 2010. 196-202. Print.

[8] Egenfeldt-Nielsen, Simon. "Practical barriers in using educational computer games." On the Horizon 12.1 (2004): 18-21. On The Horizon. Web. 16 May 2012. <http://www.emeraldinsight.com/10.1108/ 10748120410540454>.

[9] Magnussen, R. "Teacher roles in learning games. When games become situated in schools." In A Baba, (Ed.) Learning. Tokyo: University of Tokyo, 2007. 610-615. <http://www.digra.org:8080/Plone/ $\mathrm{dl} / \mathrm{db} / 07312.54512$.pdf $>$

[10] McFarlane, Angela. "Professor Angela McFarlane, BLC07 Keynote | November Learning." November Learning | Education Consulting, Workshops and Conferences. 10 July 2007. Web. 28 Aug. 2012. Audio.http://novemberlearning.com/ professor-angela-mcfarlane-blc07-keynote/.

[11] Chen, B. S., and D Michael. "Proof of Learning : Assessment in Serious Games." Media October .19 (2007): 29 - 33. Gama Sutra. Web. 17 May 2012. <http://www.gamasutra.com/features/20051019/chen_ 01.shtml>

[12] Hickey, Daniel T, Ellen Jameson. "Designing for participation in immersive educational videogames." In Dirk Ifenthaler, D. Eseryl, X. Ge (Eds.). Assessment in game-based learning foundations, innovations, and perspectives. New York: Springer, 2012. 401-430. Print.

[13] Ito, Mizuko. "Preface." In Anna Everett (Ed.) Learning race and ethnicity: youth and digital media. Cambridge, Mass.: MIT Press, 2008. vii-ix. Print.

[14] Zuckerman, E. (n.d.). Ethan Zuckerman: Listening to global voices | Video on TED.com. TED: Ideas worth spreading. Retrieved April 12, 2013, from http://www.ted.com/talks/ethan_zuckerman.html

[15] Lopez, Antonio. "Circling the Cross: Bridging Native America, Education, and Digital Media." In Anna Everett (Ed.). Learning race and ethnicity: youth and digital media. Cambridge, Mass.: MIT Press, 2008. 109-126. Print. 